\title{
SERIAL FEATURES
}

\section{Selective Primary Health Care: Strategies for Control of Disease in the Developing World. XV. Acute Diarrhea}

Diarrhea claims the lives of at least five million children per year and is a major contributor to malnutrition in developing countries. A variety of infectious agents cause diarrhea through several pathogenic mechanisms. Bacteria such as Shigella can directly invade the intestinal mucosa, and those similar to Vibrio cholerae or enterotoxigenic Escherichia coli can produce toxins that alter cellular absorption and secretions. Rotavirus appears to cause $30 \%-40 \%$ of diarrhea in toddlers. Diarrhea frequently accompanies parasitic infestation and infections in other parts of the body. Several methods, including improvement of water supplies and sanitation and administration of vaccines and antibiotics, may be useful in preventing mortality and morbidity due to diarrhea. Oral rehydration to replace fluids and electrolytes, accompanied by attention to early feeding and encouragement of breast feeding, is the most effective and economical intervention currently available.

Diarrhea, the first or second most important cause of childhood death in the world [1], is in fact not a disease but a symptom complex of multiple etiologies. Variously defined in terms of frequency and consistency of fecal passage, diarrhea is ultimately identified by the liquid nature of the stool; loss of fluid is the most important cause of death. The present article will focus on infectious agents (bacteria, parasites, viruses), which cause the vast majority of cases. In addition to claiming the lives of an estimated five million children per year [2], diarrhea is a major contributor to malnutrition through a variety of mechanisms including anorexia, intestinal malabsorption, and social practices depriving the patient of food. Prevention of diarrhea requires vast, complex, and expensive environmental improvements designed to reduce ingestion or contact with fecal organisms. Clean, protected water supplies and effective, universal sanitation systems as well as a high degree of personal hygiene must be achieved before a significant reduction in the incidence of diarrhea will occur. Even under sanitary conditions prevailing in West-

This review is the fifteenth in a series edited by Julia A. Walsh and Kenneth S. Warren dealing with selective primary health care in the developing world. This series will be published in book form by the University of Chicago Press after all of the reviews have appeared in Reviews of Infectious Diseases. Reprints will not be distributed by the author. ern nations, diarrhea remains relatively high on the list of morbid conditions affecting children. However, mortality and morbidity due to malnutrition can be prevented by cheap and readily available oral rehydration and intensified attention to the nutritional needs of the sick and convalescing child. Hospital oral rehydration units have reduced mortality to $<1 \%$, and even field programs making packaged oral rehydration salts available in the community have reduced deaths by $50 \%$ or more. The universal understanding and use of home rehydration measures, combined with effective backup services, could reduce deaths from diarrhea by $50 \%-90 \%$ and may be the most effective intervention against malnutrition among the five hundred million children of the developing world.

\section{Understanding the Problem}

The pathogenesis of diarrhea caused by infectious agents has been extensively studied. The following section will briefly review the multitude of causative agents and the various pathogenic mechanisms [3].

\section{Biology}

Bacteria. The role of bacterial toxins in the pathogenesis of diarrhea is best understood for 
cholera toxin and heat-labile toxin (LT) produced by Escherichia coli. First, the bacterium adheres to the gut wall. The toxin then fixes to binding sites (gangliosides) on the cell wall and stimulates the cellular mechanisms that produce cyclic nucleotides, which in turn both decrease the absorption of sodium from gut lumen by villus tips and increase the secretion by the crypts of sodium chloride and water from the blood to the lumen [4]. Cholera toxin and related toxins of Enterobacteriaceae, such as LT of $E$. coli, work through a cAMP mechanism characterized by a time lag in onset, nonreversibility, and subsequent continued effect for up to $48 \mathrm{hr}$, with increased crypt secretion and decreased villous absorption [5]. The heat-stable toxin (ST) of $E$. coli, on the other hand, activates guanyl cyclase to produce cGMP almost immediately, an effect that can be reversed by removal of toxin. The result is decreased absorption by villus tips, with no apparent effect on crypt mechanisms [6]. The predominant mechanism of recovery from toxin-induced diarrhea is the replacement of these affected cells by the normal regeneration of the intestinal villus [7]. Thus, toxin-induced diarrhea is self-limited, lasting from two to five days in most cases.

Shigella dysenteriae is the classic agent of invasive diarrhea [8]. The organism elaborates a variety of toxins, many plasmid-encoded, that may facilitate penetration of the mucosa of the colon [9]. $S$. dysenteriae is cytotoxic and moves laterally to invade contiguous cells. Microabscesses and denuded ulcers lead to bloody dysentery. Highly host specific, a small inoculum is infective $\left(10^{1}-10^{2}\right.$ organisms, vs. $10^{5}-10^{7}$ Vibrio cholerae or $10^{6}-10^{9}$ Salmonella organisms needed to produce infections in a majority of cases [10]). Other organisms causing invasive diarrhea (enteroinvasive $E$. coli, Campylobacter jejuni, Yersinia enterocolitica, and some Salmonella species) differ in the mechanism of mucosal penetration but may produce similar clinical symptoms, with dysentery, abdominal pain, and fever. In addition, "invasive" organisms including $S$. dysenteriae, $Y$. enterocolitica, some Salmonella species, and $C$. jejuni may produce enterotoxins that affect fluid absorption and secretion, but the role of these toxins in pathogenesis is unclear. Invasive diarrhea tends to last longer than that induced by toxin, with recovery requiring killing of infecting organisms and repair of damaged gut surface.
Enteropathogenic E. coli (EPEC) classically seen in nursery outbreaks have been identified by serogrouping [11]. Often found in similar numbers in control patients and patients with diarrhea, the importance of EPEC in sporadic cases of diarrhea is doubtful. Other bacteria associated with diarrhea, most often in food poisoning, are certain toxin-producing staphylococci, Vibrio parahemolyticus, and Bacillus cereus [12]. The socalled overgrowth of normal flora in the upper intestine is often associated with chronic diarrhea in malnourished individuals or those with sprue-like malabsorption syndromes.

Viruses. For many years, although the epidemiology of childhood diarrhea indicated an infectious origin, the incrimination of viral agents was uncertain. In the last decade, with the discovery of the Norwalk agent and rotavirus, up to $80 \%$ of diarrheal episodes in children can now be ascribed to specific etiologic agents. Norwalk and Norwalklike agents account for about one-third of epidemic outbreaks in the United States [13, 14]. Worldwide, rotavirus is present in $30 \%-40 \%$ of cases of diarrhea in children younger than two years of age [15]. Other viruses in the calicivirus, coronavirus, and adenovirus groups have been identified and implicated both epidemiologically and pathologically in smaller series of patients [16]. The consistent and continuing absence of etiologic explanation in $20 \%-40 \%$ of cases of diarrhea suggests that additional viral agents will be identified.

Intestinal viruses (rotavirus is the best studied) invade the enterocytes and lead to a flattening of the columnar epithelium of the villus tip [17]. The cuboidal cells on the blunted villi have morphologic and functional characteristics (similar to those of crypt secretory cells) that appear to explain the observed reduction in absorption and net secretion resulting in diarrhea. Recovery occurs when the mucosal surface regenerates.

Parasites. The most important protozoa known to cause diarrhea are Giardia lamblia, Entamoeba histolytica, and Cryptosporidium. Among helminths, Strongyloides and, occasionally, Trichuris have been implicated, but there is no good evidence that Ascaris, or hookworm, causes diarrhea. The mechanism of amebic dysentery is clearly related to adherence through microfilament invasion and microabscess formation [18]. The resulting diarrhea tends to be chronic, painful, de- 
bilitating, and associated with pus-containing blood.

Giardia lamblia attacks the upper intestine, and usually the duodenum. The pathogenesis of the diarrhea is unclear. The symptoms of epigastric distress, foamy stools, and foul smell suggest this diagnosis. Giardiasis has occurred in epidemic proportions, and onset can be acute or chronic [19].

Cryptosporidium, a coccidian parasite well known to veterinarians, is seen in humans most frequently in immunocompromised patients [20] but also accounts for up to $5 \%$ of childhood diarrhea ([21] and J. W. Pape, personal communication). It does not appear to be invasive and is found in the glycocalyx coating the brush border, facts suggesting a mechanism of action involving toxin. A prominent feature in aquired immune deficiency syndrome (AIDS), cryptosporidium diarrhea appears unaffected by virtually all drug regimens tested.

Other agents. Diarrhea commonly accompanies infections in other parts of the body. It has been described in conjunction with malaria, otitis media, pneumonia, streptococcal sore throat, and a variety of other common conditions. It almost invariably accompanies measles and accounts for a substantial proportion of measles-associated deaths [22]. Diarrhea is often a manifestation of intestinal tuberculosis and a variety of diseases of the liver, including cirrhosis and biliary tract disease. Poisons and various toxins, such as ciguatera toxin in tropical fish, frequently cause acute diarrhea [23].

Less frequently, especially in developing countries, a wide array of other etiologic mechanisms exist. Food intolerance, e.g., lactase deficiency found predominantly in dark-skinned people, and food allergies, especially to foreign animal protein, can cause acute and chronic diarrhea [24]. Cow's milk formula provided early in life may lead to a high degree of sensitization to cow's milk proteins and other antigens and may result in lifelong sensitivity to these agents [25]. Granulomatous diseases of the gut and tumors elaborating gastrointestinal hormones are proven causes of severe diarrhea [26]. While these must be considered in the diagnostic work-up of patients with chronic diarrhea in Western countries, where $10 \%$ or even $20 \%$ of cases are related to such noninfectious causes, they account for a negligible proportion of the 1,000 million episodes of diarrhea occurring in the world each year [27], for which infection is the cause of all but a small percentage.

\section{The Individual}

Fluid and electrolytes. Diarrhea, whatever the etiology, precipitates acute fluid and electrolyte malnutrition (FEM) [28]. The acute loss of fluid and body salts leads to dehydration and, in some cases, death. Fluid losses in cholera can exceed 20 $\mathrm{ml} / \mathrm{kg}$ per hour, a rate that rapidly leads to extreme hemoconcentration and shock. Usually fluid loss is slower. The composition of the lost fluid depends on the age of the patient, the rate of stool loss, and the causative agent. Younger children tend to lose more potassium and less sodium in their stools. The higher the rate of stool loss, the more the sodium electrolyte level tends to approach serum level [29]. This is probably a result of rapid passage through the colon, where sodiumpotassium exhange occurs. Stools of patients with cholera or $E$. coli infection contain sodium in a concentration of $80-120 \mathrm{meq} / \mathrm{liter}$, while those of patients with rotavirus infection have a sodium concentration consistently $<50 \mathrm{meq} / \mathrm{liter}$.

Nutrition. Of all common childhood illnesses, diarrhea has the most important adverse nutritional effect $[30,31]$. Mechanisms contributing to malnutrition include decreased absorption of nutrients, tissue breakdown through fever, activation of hormone-mediated catabolism, and decreased food intake due to sociologic factors as well as anorexia. During an episode of diarrhea, absorption of fats diminishes by as much as $50 \%$, although the absorption of carbohydrates diminishes by $<20 \%$ [32]. Gastrointestinal protein loss has been documented in diarrhea caused by $S h i-$ gella, rotavirus, and enterotoxigenic $E$. coli (but not in that due to V. cholerae) [33] and may be so extensive in measles as to precipitate the acute onset of kwashiorkor [22]. Most toxin-induced diarrhea is not accompanied by fever. The illness represents a derangement of intestinal luminal mechanisms rather than a systemic infection per se. Fever, however, does characterize many of the invasive diarrheas, including that caused by rotavirus, especially in the early stages of infection [34]. These factors contribute to the catabolic state. Whitehead et al. [35] postulate that the increased 
level of corticosteroids found during frequent diarrhea in Gambian children is a major factor in the development of marasmus in this population.

In almost all societies, diarrhea is an accepted indication for reduced food intake. The anorexia associated with diarrhea also seems to play a major role in inducing malnutrition. Careful dietary measurements have now shown that a child with diarrhea will eat only $30 \%-70 \%$ of his normal intake, even when encouraged [36]. The mechanisms involved in anorexia are unknown. Electrolyte imbalance, especially hypokalemia, and dehydration reduce appetite.

Taken together, catabolism, malabsorption, and the lack of food intake may cause a child with diarrhea to lose $2-5 \mathrm{~g} / \mathrm{kg}$ of body mass per day (i.e., a decline of $\sim 20-50 \mathrm{~g}$ for each day ill). For children in whom normal monthly weight gain (growth) between ages one and five years is 170$200 \mathrm{~g}$, regression analysis of weight loss against days ill with diarrhea shows a net loss of 500-700 $\mathrm{g}$ per 30 days ill [30]. Annual incidence of diarrhea in weaning children varies from two to 12 episodes lasting from three to seven days [27]. The measured point prevalence of diarrhea in children of $5 \%$ $15 \%$ indicates that children in developing countries are ill with diarrhea for an average of 20-60 days per year [37]. Thus, annual weight deficit attributable to diarrhea may be between 400 and $1,500 \mathrm{~g}$, or $25 \%-75 \%$ of expected growth. Compounded over the first five years of life, diarrhearelated nutritional deficits alone can leave a child in second- or third-degree malnutrition.

Immune response. Immune mechanisms particularly related to the intestine involve antigen processing by lymphocytes in the lamina propria, with formation of specific antibody, particularly of the IgA secretory class. Stimulated lymphocytes have been shown to travel through the central lymphatic system and to home specifically to Peyer's patches, salivary glands, and mammary glands [38, 39]. Thus, a lactating mother secretes milk with both secretory antibodies and activated macrophages directed specifically against the antigens in her own intestine [40]. Production of certain milk antibodies can be induced by feeding antigen to the mother, and these appear to protect the nursing child. For instance, nursing infants of mothers with cholera have a very low incidence of cholera [41]. However, the role of intestinal immunity in protection from infection is still largely unknown, and its potential virtually unexploited.

Systemic antibodies are formed against numerous agents. While these allow useful diagnostic tests, particularly where rises in titer can be documented (infections involving rotavirus or the Norwalk agent, cholera, amebiasis), their role in recovery and subsequent protection is variable. Cholera toxoid, although protective in laboratory settings, has not been an effective immunogen in field trials [42]. Antibodies against cholera somatic antigens appear to be protective at least when high titers are achieved, and volunteers infected with cholera are immune to repeat challenge [43]. Protection by natural infection is, however, not complete, and in endemic regions repeat cholera infection does occur [44].

Acquired immunity appears to explain the lower attack rates for most diarrheal diseases in adults. While epidemic cholera attacks all age groups, in endemic areas children are by far the group most affected. Diarrhea due to rotavirus is confined almost exclusively to the very young. While immune protection in cholera appears to be partial [44], that following rotavirus infection may be lifelong. For most diarrhea of bacterial or parasitic origin, infection and disease do not appear to protect against future infection with the same organism.

Host response. Recovery from diarrhea is related to elimination of the offending agent and to regeneration of damaged intestinal epithelial cells. In the case of simple infection with rotavirus or poisoning of cellular mechanisms by toxins, this regeneration effectively takes only several days, thus accounting for the normally limited duration of most diarrhea. However, a certain proportion of cases will become chronic, with associated food intolerance and a continued malabsorption of both nutrients and fluids.

\section{The Population}

From the United States to India, from South Africa to the Arctic, diarrhea is common and the incidence is variously estimated from as few as one to as many as twelve or more episodes of diarrhea per child per year [45]. Obviously the incidence varies with the environment as well as with the definition, perception, and observation of illness. The World Health Organization (WHO) estimates that 
744-1,000 million episodes of diarrhea occur every year among the world's 338 million children younger than age five [27]. The age-specific incidence appears closely associated with the introduction of weaning food, peaking in the second half of the first year of life and diminishing constantly thereafter. Adults generally suffer fewer than one episode per year, a rate estimated rather than documented in most parts of the world. Microbiologic studies of weaning foods in The Gambia show a large inoculum of potentially pathogenic bacteria, and a corresponding peak in incidence of diarrhea, associated with weaning foods [46].

Babies fed milk from bottles are exposed to large inocula of bacteria [47] and, in all reported studies, have much higher rates of diarrheal disease and death than do their peers fed exclusively breast milk [48]. The earlier the bottle is introduced, the higher the risk. In an urban slum of Port-au-Prince, Haiti, children fed with a bottle during the first month of life had five times the risk of death in the next 17 months as did a cohort group exclusively breast-fed in the first month [49].

Malnourished children have a higher incidence and suffer more severe disease than do their betternourished peers [50]. Malnourished children are more susceptible to a given challenge, have higher exposure to environmental pathogens, and have reduced intestinal function, which leads to more severe fluid and nutrient losses.

Using estimates for global protein-energy malnutrition (PEM) and relative risk of diarrhea, the author has estimated that up to $30 \%$ of cases of diarrhea are related to the increased incidence found among malnourished children [37]. On the other hand, the crude estimate of the nutritional impact of the 1,000 million episodes of diarrhea in the world per year, with an average weight deficit of 400-1,500 g per child by age five years, shows the tremendous contribution to malnutrition made by diarrhea. Thus, the commonly recognized interaction of diarrhea and malnutrition, the FEM-PEM cycle [28], is an important part of the epidemiology of diarrhea.

Infectious diarrhea is transmitted by the ingestion of fecal organisms. Conditions encouraging contact or spread of feces are invariably associated with higher incidence. The epidemiology varies extensively according to etiologic agent. For highly host-specific organisms that require a small mean inoculum size to cause infection (such as Shigella species), person-to-person contact is important, and spread can be controlled through improved personal hygiene [51]. In urban Bangladesh, provision of soap and intensive education to households of patients with dysentery reduced secondary attack rates in comparison with rates in a matched control group [52]. Soap and water can work, if used correctly. Where wide host ranges allow animal carriers and where higher inocula are required (such as for Salmonella, E. coli, and Campylobacter), the importance of food and water contamination is greater [53]. In addition, host responsiveness changes with age. The rotaviruses are by far the major pathogens in children younger than two years of age [54]; toxigenic $E$. coli is particularly important among travellers and adults in tropical areas [55]; and cholera affects all ages in epidemic virgin areas but predominantly attacks children in endemic areas [41].

The epidemiology of diarrhea gives important clues to specific etiology and defines risk groups, seasonality, and environments where interventions are most likely to be effective. It indicates the useful strategies for control.

\section{Points of Attack}

Because diarrhea results from many different etiologies, several different points of intervention are available. Depending on the cause of diarrhea, which determines the effectiveness of the method chosen, the following points of attack should be considered: $(I)$ prevention of contact with the infecting agent; (2) prevention of infection through the use of vaccines; (3) breast milk protection; (4) interference with the mechanisms of diarrhea; (5) use of antibiotics; (6) replacement of sodium, bicarbonate, potassium, substrate, and water losses; and (7) convalescent nutritional care.

\section{Methods of Attack}

\section{Prevention of Contact with the Infecting Agent}

Interruption of the fecal-oral transmission of diarrhea is accomplished through widespread introduction of effective clean water supplies, personal and food hygiene, and sanitary waste disposal [56].

The effectiveness of environmental and public health measures has been proved more by histori- 
cal examples than by carefully controlled studies. Best known is the control of cholera in London by improvement of public water supplies. It is notable, however, that while cholera largely disappeared from London with the assurance of clean water in the mid-19th century, the infant mortality in London during 1904 was still $>120$ [57], a rate that exists today in many developing countries where public water supples are virtually nonexistent. Diarrhea, which accounted for more than one-half of the elevated rate in London, fell only with the adoption of personal hygiene practices that took two to three generations to be generally accepted by the English public. Similar reduction in mortality from diarrheal diseases was seen in the United States in the first half of the 20th century, a change that took almost 50 years after reliable public water and sanitary facilities became universally available [58].

In general, the impact of rural water and sanitation systems has been difficult to measure and often has not been apparent [53]. Not only must water be provided in large quantities in the household, but habits regarding personal hygiene must be developed to ensure interruption of fecaloral transmission. Fear of the "fecal peril" is a learned emotion, taking years to instill within a culture that views body waste as merely a part of nature. A recent WHO review of the literature shows that abundant clean water supplies, or clean water provided very close to the home, has in some studies been associated with decreased incidence of diarrhea [53]. However, the most consistently positive results were seen in communities in the United States and a few Third World areas, where demand for and use of water was affected by long cultural indoctrination on its proper use to avoid disease. Many other attempts to reduce diarrhea by improving water availability and quality have failed [59]. Reasons are numerous and complex and include technical inadequacies (broken pumps, leaking pipes, unprotected sources), improper use (storage of clean drinking water in unclean domestic containers), and deep cultural constraints (river water tastes better).

The impact of sanitary waste disposal is even more difficult to document. While a latrine program in an urban slum in the Philippines reduced the incidence of cholera, no impact was seen on acute non-cholera-associated diarrhea [60]. These results are less surprising when one recalls that the major burden of diarrhea is by far on the very young, with the age-specific incidence peaking before age two years. Children in this age group are generally not users of latrines or even clean water, and they are often the most exposed to the ground, the dirt, and the contamination in the environment. Nothing short of an immaculate environment is likely to prevent this group from gaining access to the organisms causing diarrhea.

Inadequate refrigeration of stored foods encourages growth of organisms causing acute food poisoning. Salmonella organisms are spread through the mass processing of poultry. Vibrios can be found in raw shellfish from contaminated waters, and all fruits and vegetables can carry pathogens when washed in sewerage-contaminated water. Control of these factors is part of the complex health regulations of the food chain necessary to interrupt transmission of diarrhea-causing pathogens.

\section{Prevention of Infection Through Use of Vaccines}

While existing cholera vaccine does afford some protection, perhaps $>50 \%$ for a period of up to six months, it is not effective in reducing transmission of the disease, nor does it alter the course of the illness [61, 62]. Cholera in patients with or without pre-existing antibodies is equally severe [63]. Newer vaccines combining somatic and toxoid antigens may offer improved protection [42]. More promising still is the production of mutant vibrios that secrete only the B chain of cholera toxin (the natural immunogenic toxoid); this process may allow development of an oral vaccine that would better mimic natural immunity [64].

Orally administered vaccines against Shigella have been found effective in field trials but require five doses and repeat booster doses, making mass use still impractical [65]. Although the Ty21a oral typhoid vaccine appears to offer high protection, even with a single dose [66], there are still no vaccines for the 1,500 or more known types of common Salmonella.

With the identification of rotavirus as a major cause of fatal diarrhea in young children, strong efforts have been made to produce a vaccine against this virus, which appears to have only two or perhaps three serotypes [67]. The highly limited, age-specific rate of attack of this virus suggests that immune mechanisms are indeed protective, 
and vaccines are a possible future intervention [68].

Recombinant DNA technologies make production of a wide variety of specific antigens possible and open the way for eventual polyvalent vaccines aimed against a host of organisms. For now, in view of the wide range of etiologic agents and the difficulty of eliciting effective immune protection for each, the likelihood of effective vaccination coverage against diarrhea in developing countries is small. However, if protection from specific diseases of high prevalence and importance (particularly those caused by rotavirus, the toxins $E$. coli, $V$. cholerae, and Shigella) could be provided simultaneously, mass vaccination programs may become a reasonable, cost-effective intervention.

\section{Breast Milk Protection}

The remarkably high level of protection from diarrhea of a nursing infant is due to a myriad of factors, which have been extensively reviewed [48]. Not only do specific immune factors in mother's milk (macrophages, antibodies, lactoferrin) protect the child, but, perhaps more importantly, the child is not exposed to the heavy contamination of the feeding bottle [47]. Unclean water, utensils, and hands all contribute to the high bacterial count found in milk. Furthermore, absence of refrigeration and the general need to save unused milk until a later feeding make bacterial proliferation inevitable in this ideal culture medium. The impact of breast milk on reducing the incidence of diarrhea among those most vulnerable makes active promotion of breast feeding one of the most essential methods of intervention.

\section{Interference with the Mechanisms of Diarrhea}

A number of antisecretory drugs (aspirin, indomethacin, prostaglandins, chlorpromazine, loperamide) working through a variety of mechanisms in the mucosal cell have been shown to diminish or reverse the secretory process and, therefore, effectively reduce loss of fluids and electrolytes [69]. It is important to note, however, that in no case has this reduction been clinically very significant, nor has it obviated the need to replace fluids and electrolytes lost before therapy begins. Chlorpromazine reduces fluid losses in cholera, but this reduction is no greater than that seen by the use of tetra- cycline, an antibiotic that effectively eliminates the organism from the gut $[70,71]$.

Antimotility agents (opiates, Lomotil) may increase duration of secretion of fluid, prolong passage of pathogens, increase fever and fever-related catabolism, and decrease absorption of nutrients through stasis and pooling in the gut [72]. Traditional wisdom notwithstanding, there is no evidence for an inverse relationship of gut transit time and nutrient absorption in acute diarrhea. Antimotility agents should not be used, except for control of severe cramps and tenesmus in children above infant age. Absorbents (Kaolin, charcoal) have no demonstrated effect on either duration or severity of diarrhea [73]. While not apparently harmful, they detract from more important therapy and should be avoided. Thus, while the pathophysiology of diarrhea offers numerous potential points of intervention, careful research and documentation of efficacy and safety are still needed before any can be recommended.

\section{Antibiotics}

Use of antibiotics has been shown in most studies of undifferentiated acute diarrhea to be ineffective and may in some cases lead to prolongation of the diarrhea [74]. Prophylactic antibiotics are contraindicated for people living in endemic areas and will only lead to the development of resistant organisms.

Initial enthusiasm for the iodated chloroquine derivatives (Vioform) was not based on careful experimental evidence of efficacy. In fact, these agents appear to be of no value in any but amebic diarrhea, and even then are not drugs of choice. Drug toxicity with retinal degeneration has proved a high risk for such an ineffective agent [75].

In cases in which the invasive organism causes a dysentery-like syndrome, antibiotics are indicated, the specific choice being based on knowledge of the sensitivity patterns of pathogens cultured in the same locale. Common choices are trimethoprim-sulfamethoxazole, ampicillin, or tetracycline for presumed Shigella infection [8], doxycycline or erythromycin for Campylobacter infection [75, 76], chloramphenicol for severe Yersinia infection [77], and tetracycline and metronidazole for amebic dysentery. Metronidazole is also the drug of choice for Giardia infection.

For the acute, watery diarrheas, only in cholera 
is tetracycline, chloramphenicol, or furazolidone indicated. For infections due to $E$. coli, rotavirus, and unknown pathogens, which together account for $90 \%$ of cases, antibiotics are not useful and can lead to harmful overgrowth of organisms such as Clostridium difficile, with attendant necrotizing colitis [78].

Studies of hundreds of cases of undifferentiated acute diarrhea randomly treated with either antibiotics or only fluid therapy show no difference in duration of illness, quantity of stool, duration of fever, or rate of recovery $[74,79]$.

\section{Replacement of Losses}

The most effective available interventions to reduce death and morbidity are efforts to offset the effects of acute diarrhea: the loss of fluid and electrolytes and the reduction of nutrient intake. The development of oral fluid therapy for diarrhea, which was an outcome of research in cholera, demonstrated the high efficacy of replacement of water and electrolytes with an appropriate, absorbable substrate, thereby of fsetting the effects of dehydration and substantially reducing numbers of deaths. When this technique is used properly, case fatality is reduced to $<1 \%$, and in experienced hands reaches one case per thousand population.

Extensive reviews have documented both the scientific basis and the efficacy of oral rehydration therapy (ORT) in acute diarrhea [80-82]. It is safer and more effective, as well as far cheaper, than intravenous fluid replacement [83]. The ORT formula developed by WHO has proved effective and safe in the treatment of millions of cases throughout the world. When available in hospitals and clinics, treatment is effective, safe, and remarkably cheap. Fatality occurs only in untreated patients presenting late in the course of infection and who are in severe shock on arrival. For this reason, the greatest emphasis should be given to replacement of fluid and salt losses as early as possible in the illness, before the appearance of dehydration. Thus availability and acceptability of rehydration measures and accessibility of necessary supplies or ingredients are even more critical than precise composition of the resulting formula. Whenever possible, the "complete formula" should be provided, and compromises should be made only in order to ensure greater acceptance and more widespread coverage.
Sodium. The $90 \mathrm{meq} / \mathrm{liter}$ solution of sodium is effective in all diarrheal diseases including cholera. It is designed as a rehydrating fluid with sodium concentration adequate to expand extracellular space and restore normal circulation. It is effective for all ages, but in infants especially, it must be supplemented with low-sodium fluids, preferably breast milk or, in its absence, dilute feeds or even plain water. Solutions containing less sodium (50-60 meq/liter), while not effective in the severe secretory diarrheas like cholera and less effective in rehydration, have been used effectively in trials in several countries and may offer a wider margin of safety from electrolyte disorders in infants [84].

Bicarbonate, citrate, or other base. While acidosis invariably accompanies significant fluid loss, the severity is directly related to both volume of diarrhea and degree of dehydration. Thus, early water and salt replacement to avoid dehydration can reduce acidosis even in the absence of base. The acidosis will then resolve through normal renal and respiratory compensatory mechanisms over several days. While the effects of prolonged hypocarbia are not known, it is preferable to provide some base in rehydration solutions; the $30 \mathrm{meq} / \mathrm{liter}$ of base in the WHO solution is adequate to correct losses, yet not so high as to cause alkalosis. Acetate and citrate are acceptable alternatives to bicarbonate and are easier to incorporate in packaged or tablet preparations of ORT [81], thereby offering the prospect of reduced costs and longer shelf life.

Potassium. Although the deficit of total body potassium characterizing malnutrition is invariably exacerbated by acute diarrhea because of acidosis and extracellular shifts of potassium, this may not be apparent in serum measurements made at admission [80]. Potassium losses in diarrhea are high, especially in infants, and optimal rehydration fluids contain a minimum of 20 meq/liter (WHO formula); higher concentrations have been advocated in several studies [84]. As hypokalemia is associated with apathy, decreased appetite, adynamic ileus, and general disturbance of smooth muscle systems, especially in the early stages of dehydration, replacement is an important part of both electrolyte and nutritional therapy. Greater efforts are needed to identify local sources of highpotassium foods and to encourage their use during both home rehydration and convalescence. The 
specific effect of low levels of total body potassium on appetite, however, needs to be defined.

Substrate. An absorbable concentration of $2 \%$ glucose ( $20 \mathrm{~g}$ of glucose or $40 \mathrm{~g}$ of sucrose/liter) is required for optimal absorption of the salt-water solution. Unfortunately, higher concentrations of sugar are not well tolerated because of high osmotic activity that often exacerbates diarrhea. Thus, ORT provides very few calories (8-16 $\mathrm{kcal} / 100 \mathrm{cc})$ at a time when increased energy sources are badly needed. New research in hypoosmotically active substrate sources such as cereal powders, in which long-chain molecules (dextrins, starch) provide glucose at virtually no osmotic cost, are extremely promising. Using $30 \mathrm{~g}$ of rice powder/liter, Molla et al. [85] demonstrated less stool output and better urine flow than with the use of standard ORT containing sucrose [85]. More avid absorption, earlier reduction in stool output, and faster recovery are seen when the starch concentration is $5 \%$, a level unreachable with simple sugars because of the osmotic diarrhea that would result [86].

Observations of the effectiveness of Kwashiorkor Mix (K-Mix) for the therapy of kwashiorkor showed marked reduction in deaths from diarrhea and hypoglycemia [87]. This easily absorbed, simple carbohydrate (sucrose) combined with casein hydrolysate (a source of small polypeptides) in a liquid mixture contributes to both nutrition and fluid absorption simultaneously. In Haiti, Drs. Pape and Rohde are using a dilute solution of KMix with electrolytes for rehydration. Patients can be discharged an average of $18 \mathrm{hr}$ earlier than those rehydrated with and maintained on the WHO formula, and they show better weight gain, since high nutrient intake is initiated on admission. This observation supports earlier work on the synergistic effects of glycine and glucose in an ORT solution $[88,89]$. Inclusion of more nutritious substrates absorbed by various noncompeting pathways offers the prospect of a more efficacious and nutrient-dense rehydration solution. Cereals, legumes, and other locally available, simple foods may thus become, in proper quantities, the basis of a combined fluid-protein-energy oral therapy for diarrhea, a single antidote for the FEM-PEM cycle.

Water. The quantity of water used to mix ORT is as critical to final composition as is the measurement of solutes, an obvious but often overlooked fact. Each country should identify the most widely available, reproducible volume measure and adapt packaging or homemade formulas to this standard measure. Larger volumes (in the range of one liter) have the advantage of cheaper packaging and less percentage variation in final volume, whereas smaller volume standards are less subject to bacterial growth through standing; smaller standards also reinforce messages encouraging volume-forvolume replacement of losses ("one loose motion, one glass of ORT"). However, the small packet may incorrectly suggest to the mother that this amount is sufficient to treat diarrhea.

The best quality water available should be used to prepare ORT, but standards of purity that inhibit the use of ORT should be avoided. There is no evidence that ingestion of ORT dissolved in normally consumed water is any more detrimental than the routine daily risk of imbibing water alone [90].

While the efficacy of ORT is unquestioned, present efforts are focused on developing the most efficient methodologies to deliver this intervention to each child early in the course of diarrhea. The most successful programs have provided ORT at home, where high acceptance has led to the greatest decline in mortality. When ORT use has been confined to medical facilities, or not used early or in adequate quantities, the impact has been less [91]. Salt-sugar mixtures have been shown to be effective in treating dehydration, although when started late in the illness, they will not correct acidosis [92]. When distributed to households in one large Egyptian study, salt-sugar packets were as effective as ORT in reducing the number of deaths due to diarrhea by $\sim 50 \%$. Large, carefully controlled field trials of salt-sugar mixtures vs. ORT are awaited, but most studies indicate that early replacement of losses is a key to effective impact, even if salt-sugar is the only solution available. Home mixtures made either with household implements or special plastic measuring tools result in solutions of acceptable composition in most studies [94, 95]. Mixing errors appear no more likely with home mixtures than with packaged ORT.

Large programs in the Philippines, Indonesia, Bangladesh, Haiti, and Egypt are attempting to introduce a tiered system whereby fluid therapy is initiated by the mother at home using salt, sugar, and water; early self-referral to a community dis- 
tribution point for the complete packages of ORT is encouraged; and back-up health services are available for persistent and more severe cases. Such a graded system is likely to have the greatest coverage, highest acceptance, lowest cost, and, therefore, greatest overall impact on mortality.

Moreover, it appears from studies in the Philippines [96], Turkey [97], Iran [98], and Egypt [99], as well as from studies of Apaches [100], that early rehydration leads to a diminished negative nutritional impact of diarrhea, perhaps because of improved food intake and absorption. In programs where oral rehydration is accompanied by strong nutritional advice, continued feeding of the child, and attention to food in early convalescence, improved nutritional status has been associated with the use of oral therapy [101]. Thus ORT can provide both a dramatic reduction in mortality and a reduction of malnutrition.

\section{Convalescent Care}

While nutritional care following acute diarrhea is conceptually a part of convalescent care after oral therapy, it is important to note that convalescent care may in itself be an important intervention, reducing the subsequent incidence of diarrhea [37]. Immediately following the cessation of diarrhea, there is an apparent rise in appetite, often to supranormal levels, as shown by studies of food consumption in hospitalized patients. Molla et al. [102] have demonstrated appetite recovery as evidenced by spontaneous consumption of recommended dietary allowance (RDA) quantities or more of usual foods on days 4-7 following acute diarrhea due to rotavirus, enterotoxigenic $E$. coli, $S$. dysenteriae, and $V$. cholerae. Supranormal appetite with intake exceeding $130 \mathrm{kcal} / \mathrm{kg}$ of body weight has been documented in several hospital studies.

The evidence suggests that the deficits are roughly equal to the amount of food not consumed. This quantity of food should be consumed following cessation of diarrhea within a period no longer than two to three times the duration of illness [103].

There is evidence that adequate feeding results, even before significant gains in weight, in a reduced susceptibility to further episodes of diarrhea and thus an improvement in the overall diarrheamalnutrition cycle [104]. Increased emphasis on feeding during convalescence could lead to a reduction of up to $50 \%$ in subsequent attack rates in these children. Nutrition interventions, targeted for brief periods in convalescing children, offer a greater nutritional impact both through rapid catch-up growth during the week or so after illness and through prevention of future episodes of diarrhea and resulting nutritional losses.

\section{Program Options}

Obviously, no single intervention is best. All are operative and contribute to reduction in morbidity, mortality, or both. Unit costs vary widely with actual programs, and for many the estimate is at best a guess. Per capita cost of water varies from $\$ 20$ to $\$ 50$ (U.S.) for capital investment, with a $10 \%$ annual maintenance cost. Impact on diarrhea depends upon etiology, age groups, habits, and the water system itself. Water supply systems have no apparent effect on rates of attack of rotavirus, have very little effect on the youngest age groups, depend on proper use for any effect at all, and are useless when broken down. Water was piped throughout London in the mid-19th century, but rates of death due to diarrhea remained constantly high until the first decade of the 20th century [105]. Clean, abundant, available water is a necessary prerequisite for sustained reduction in incidence of diarrhea, but its high cost and uncertain impact make it a long-range strategy at best.

Latrines have even less to recommend them as short-term means of controlling diarrhea. Pit or water seal units have an initial cost of $\$ 5-\$ 10$ per capita, and costs for more sanitary designs are higher. While they clearly contribute to the quality of the environment, sound evidence for their contribution to reduction in incidence of diarrhea is lacking. Only in the case of cholera is a good study demonstrating an impact available [60], and this same study showed no reduction in incidence of diarrhea of other etiologies. Ultimately, human behavior must change and people must actively seek to avoid fecal contamination. No study has yet documented an effect of health education on diarrhea incidence, but few workers doubt the necessity of sustained efforts to change personal habits. Design and cost of such social changes are inestimable.

Vaccines cost only $\$ 0.10-\$ 0.25$ per dose, but delivery, especially in rural areas, may cost $\$ 2$ or 
more. Even this expense might be worthwhile if effective vaccines were available, but even vaccine against $V$. cholerae, the oldest bacterial vaccine in medicine, is so ineffective that treatment of cases is cheaper and more efficacious [106]. No vaccines exist against the agents of $90 \%-95 \%$ of diarrhea cases.

No one knows the price of encouraging breast feeding, but its value is unquestioned. The economic value of breast milk to a developing country is itself a major reason to encourage breast feeding [107]. Where bottle feeding is prevalent, no other intervention offers such promise for saving lives and reducing malnutrition in the very young.

Antibiotics are of use only to protect short-term travelers in tropical countries against enterotoxigenic $E$. coli and to treat the relatively few cases of dysentery.

By far the best buy is oral rehydration. At a cost of $\$ 0.10$ per liter of ORT and $\$ 0.20$ per episode, the material cost to treat $1,000-1,500$ million cases annually is substantial: $\$ 200-\$ 300$ million. Cost per life saved, assuming a $50 \%$ effectiveness rate, is $\$ 40-\$ 120$, and this does not include the delivery cost of ORT packages, which is undoubtedly five to 10 times as much. For this reason, developing countries are seeking strategies for using homemade solutions to manage the majority of cases, while providing the more severe cases $(\sim 15 \%)$ with access to ORT packages and management by health personnel. The unit cost per death averted or per unit improvement in nutrition can thus be minimized. This is by far the most cost-effective strategy.

Convalescent nutritional care - the provision of additional food during the early recovery from diarrhea-requires a hypothetical cost structure based on the known growth rates during recovery from illness. Normally, efficiency of conversion of food energy to lean body mass is $\sim 5 \mathrm{kcal} / \mathrm{g}$ of tissue above basal metabolic needs [108]. This efficiency may be raised in the malnourished but is lowered by malabsorption or factors that divert the food from the target child. Given the estimated nutritional cost of diarrhea in preschool children in the developing world as $400-1,500 \mathrm{~g}$ per year, some 2,000-7,500 kcal of balanced diet are needed to replace this deficit. Provided as a daily average, this is a negligible quantity of food: $5-20 \mathrm{kcal} /$ day. Even if concentrated in convalescent periods, it is a small amount, costing perhaps only $\$ 1-\$ 2$, de- pending on the diet. By the avoidance of the nutritional consequences of diarrhea, subsequent attack rates could be reduced by up to $30 \%$ (although a more likely reduction is $15 \%-20 \%$ ). Thus, while such targeted feeding is likely to have the greatest nutritional impact at least cost, its contribution to lowered diarrhea incidence and mortality would be small, but not negligible.

Coverage of the population at risk is a factor of key importance; for all interventions, total impact is a product of effectiveness times coverage. Even choices within an intervention strategy must be made with this element in mind. Compromises are needed that may well accept decreasing effectiveness in favor of increasing coverage to a large enough degree to give a greater overall impact. Thus, in oral rehydration therapy it may be that homemade sugar-salt solutions so greatly increase the coverage that any reduced effectiveness in comparison to packaged solutions is negligible; the cost of providing pure water may preclude delivery of adequate volume, which is essential to maximizing health effects; or the money spent on water and latrines for a small portion of a population could provide nearly total coverage of an ORT and convalescent feeding program. The trade-offs are quantifiable in terms of costs and relative effectiveness in reducing diarrhea incidence and mortality.

In addition, cultural and social adaptation must be made in employing each of these interventions to make them acceptable and used widely and properly in the target population. This applies to water systems, latrines, and vaccinations as well as to oral therapy and feeding. The credibility of any intervention, i.e., its cultural acceptability and use by the population, will determine its overall impact to a large degree. A communication strategy supporting each intervention must be considered as an important part of extending the impact. Recent studies in Honduras and The Gambia have demonstrated a high level of acceptance and use of ORT where it has been promoted by a comprehensive media and personal outreach strategy [109]. Social marketing using modern mass communication techniques can result in affordable and significant behavioral change.

\section{Research}

Research is a legitimate intervention strategy, since 
it may be the most cost-effective means of identifying and implementing improved programs. Research in basic sciences aimed at a wide range of understanding of the pathogenesis, pathophysiology, epidemiology, and sociology of diarrhea is appropriate. A study of anticolonization factors, the development of organisms containing antigens common to multiple pathogens (possibly through genetic engineering), the control of subcellular mechanisms responsible for fluid and nutrient absorption and secretion, a better understanding of the mechanism of recovery from the various types of diarrhea, and elucidation of ultimate pathways of nutrient and fluid absorption may lead to improved therapeutic modalities. As key antigenic structures are defined and appropriate genomes transferred to carrier bacteria, vaccines will become available for many known pathogens. Knowledge of nutritional requirements and ways to overcome anorexia and a more detailed understanding of compensatory growth following illness are necessary to overcome the nutritional impact of diarrhea. Better ways to make oral rehydration socially and culturally acceptable and administrative mechanisms to deliver this known technology should be studied and developed. Similarly, communication strategies to gain wider acceptance of the use of oral fluids and of increased nutrient intake are needed. Social and anthropologic studies must define the responses to diarrhea in order to make more appropriate our intervention strategies. The cost of these research efforts cannot be gauged by expected benefits, but all hope of finding widely effective means to reduce diarrhea morbidity at affordable cost lies in areas requiring research.

\section{References}

1. Walsh JA, Warren KS. Selective primary health care: an interim strategy for disease control in developing countries. N Engl J Med 1979;301:967-74

2. Rohde JE. Why the other half dies: the science and politics of child mortality in the third world. Assignment Children 1983; 61/62:35-67

3. Diarrhea Dialogue 1981;7:6

4. Field M. Regulation of small intestinal ion transport by cyclic nucleotides and calcium. In: Field M, Fordtran JS, Schutz SG, eds. Secretory diarrhea. Bethesda: American Physiological Society, 1980:21-30

5. Field M. Cholera toxin, adenylate cyclase, and the process of active secretion in the small intestine: the pathogene- sis of diarrhea in cholera. In: Andreoli TE, Hoffman JF, Fanestil DD, eds. Physiology of membrane disorders. New York: Plenum Press, 1978:877-99

6. Hughes JM, Murad F, Chang B, Guerrant RL. Role of cyclic GMP in the action of heat-stable enterotoxin of Escherichia coli. Nature 1978;271:755-6

7. Pierce NF, Greenough WB III, Carpenter CC Jr. Vibrio cholerae enterotoxin and its mode of action. Bacteriological Rev 1971;35:1-13

8. Levine MM. Bacillary dysentary-mechanisms and treatment. Med Clin North Am 1982;66:623-38

9. Keusch GT. Shigella infections. Clin Gastroenterol 1979;8:645-62

10. Keusch GT. Ecological control of the bacterial diarrheas: a scientific strategy. Am J Clin Nutr 1978;31:2208-18

11. Bishop RF. Spectrum of infectious agents in acute diarrhea. In: Chaddwick VS, Phillips FS, eds. Gastroenterology. Vol. 2. The small intestine. London: Butterworth Scientific, 1982;319-31

12. Takeda Y. Thermostable direct hemolysin of Vibrio parahaemolyticus. Pharmacol Ther 1983;19:123-46

13. Kapikian AZ, Kim HW, Wyatt RG, Cline WL, Arrobio JO, Brandt CD, Rodriguez WJ, Sack DA, Chanock RM, Parrott RH. Human reovirus-like agent as the major pathogen associated with "winter" gastroenteritis in hospitalized infants and young children. N Engl J Med 1976;294:965-72

14. Greenberg HB, Valdesuso J, Yolken RH, Gangarosa E, Gary W, Wyatt RG, Konno T, Suzuki H, Chanock RM, Kapikian AZ. Role of Norwalk virus in outbreaks of nonbacterial gastroenteritis. J Infect Dis 1979;139: 564-8

15. Soenarto Y, Sebodo T, Ridho R, Alrasjid H, Rohde JE, Bugg HC, Barnes GL, Bishop RF. Acute diarrhea and rotavirus infection in newborn babies and children in Yogyakarta, Indonesia, from June 1978 to June 1979. J Clin Microbiol 1981;14:123-9

16. Wolf JL, Schreiber DS. Viral gastroenteritis. Med Clin North Am 1982;66:575-95

17. Davidson GP, Barnes GL. Structural and functional abnormalities of the small intestine in infants and young children with rotavirus enteritis. Acta Paediatr Scand 1979;68:181-6

18. Ravdin Jl, Guerrant RL. Role of adherence in cytopathogenic mechanisms of Entamoeba histolytica. J Clin Invest $1981 ; 68: 1305-13$

19. Smith JW, Wolfe MS. Giardiasis. Annu Rev Med 1980;31:373-83

20. Tzipori S. Cryptosporidiosis in animals and humans. Microbiol Rev 1983;47:84-96

21. Tzipori S, Smith M, Birch C, Barnes G, Bishop R. The prevalence of Cryptosporidium oocysts in hospital patients with gastroenteritis. Am J Trop Med Hyg 1983;32:931-4

22. Walsh JA. Selective primary health care: strategies for control of disease in the developing world. IV. Measles. Rev Infect Dis 1983;5:330-40

23. Morris JG Jr, Lewin P, Smith CW, Blake PA, Schneider R. Ciguatera fish poisoning: epidemiology of the disease on St. Thomas, U.S. Virgin Islands. Am J Trop Med Hyg 1982;31:574-8 
24. Sunshine $\mathrm{P}$, Sinatra FR, Mitchell $\mathrm{CH}$. Intractable diarrhoea of infancy. Clin Gastroenterol 1977;6:445-61

25. Yadav M, Iyngkaran N. Immunological studies in cows' milk protein-sensitive enteropathy. Arch Dis Child 1981;56:24-30

26. Adrian TE, Pellock JM, Bloom SR. Endocrine functions and disorders of the small intestine. In: Chaddwick VS, Phillips FS, eds. Gastroenterology. Vol. 2. The small intestine. London: Butterworth Scientific, 1982:97-118

27. Snyder JD, Merson MH. The magnitude of the global problem of acute diarrhoeal disease: a review of active surveillance data. Bull WHO 1982;60:605-13

28. Rohde JE, Northrup RS. Taking science where the diarrhea is. In: Acute diarrhea in childhood. Ciba Foundation Symposium 42. New York: Elsevier Excerpta Medica/North-Holland, 1976:339-66

29. Phillips RA. Water and electrolyte in cholera. Fed Proc 1964:23:705-12

30. Rowland MGM, Cole TJ, Whitehead RG. A quantitative study into the role of infection in determining nutritional status in Gambian village children. Br J Nutr $1980 ; 37: 441-50$

31. Chen LC, Scrimshaw NS, eds. Diarrhea and malnutrition: interactions, mechanisms and interventions. New York: Plenum Press, 1983

32. Molla A, Molla AM, Sarkar SA, Khatoon M, Rahaman MM. Effects of diarrhea on absorption of macronutrients during acute stage and after recovery. In: Chen LC, Scrimshaw NS, eds. Diarrhea and malnutrition: interactions, mechanisms and interventions. New York: Plenum Press, 1983

33. Rahaman MM, Wahed MA. Direct nutrient loss and diarrhea. In: Chen LC, Scrimshaw NS, eds. Diarrhea and malnutrition: interactions, mechanisms and interventions. New York: Plenum Press, 1983

34. Steinhoff MC. Rotavirus: the first five years. J Pediatr 1980;96:611-22

35. Whitehead RG, Coward WA, Lunn PG, Rutishauser 1. A comparison of the pathogenesis of protein-energy malnutrition in Uganda and The Gambia. Trans R Soc Trop Med Hyg 1977;71:189-95

36. Hoyle B, Yunus M, Chen LC. Breast-feeding and food intake among children with acute diarrheal disease. Am J Clin Nutr 1980;33:2365-71

37. Rohde JE. Preparing for the next round: convalescent care after acute infections. Am J Clin Nutr 1978;31:2258-68

38. Rudzik R, Clancy RL, Perey DYE, Day RP, Bienenstock J. Repopulation with IgA-containing cells of bronchial and intestinal lamina propria after transfer of homologous Peyer's patch and bronchial lymphocytes. J Immunol 1975:114:1599-1604

39. Craig SW, Cebra JJ. Peyer's patches: an enriched source of precursors for IgA-producing immunocytes in the rabbit. J Exp Med 1971;134:188-200

40. Svennerholm A-M, Hanson LÄ, Holmgren $J$, Jalil $F$, Lindblad BS, Khan SR, Nilsson A, Svennerholm B. Antibody responses to live and killed poliovirus vaccines in the milk of Pakistani and Swedish Women. J Infect Dis 1981;143:707-11

41. Gangarosa EJ, Mosley WH. Epidemiology and surveil- lance of cholera. In: Barua D, Burrows W, eds. Cholera. Philadelphia: WB Saunders, 1974;381-403

42. Craig JP. Prospects for the development of improved cholera vaccines. In: Holme T, Holmgren J, Merson MH, Mollby R, eds. Acute enteric infections in children. New propects for treatment and prevention. New York: Elsevier/North-Holland Biomedical Press, 1981:461-75

43. Levine MM, Black RE, Clements ML, Cisneros L, Nalin DR, Young CR. Duration of infection-derived immunity to cholera. J Infect Dis 1981;143:818-20

44. Woodward WE. Cholera reinfection in man. J Infect Dis 1971;123:61-6

45. Gordon JE. Diarrheal disease of early childhoodworldwide scope of the problem. Ann NY Acad Sci 1971;176:9-15

46. Rowland MGM, Barrell RAE, Whitehead RG. Bacterial contamination in traditional Gambian weaning foods. Lancet 1978;1:136-8

47. Surjono D, Ismadi SD, Suwardji, Rohde JE. Bacterial contamination and dilution of milk in infant feeding bottles. J Trop Pediatr 1980;26:58-61

48. Jelliffe DB, Jelliffe EFP. Human milk in the modern world: psychosocial, nutritional, and economic significance. Oxford: Oxford University Press, 1982:500

49. Berggren G, Eubank D, Boulos JC, Boulos LM, Mode F. Baseline survey of nutritional status of mothers and children in Cite Simone. Port-au-Prince, Haiti: USAID, 1982

50. Tomkins A. Nutritional status and severity of diarrhoca among pre-school children in rural Nigeria. Lancet 1981;1:860-2

51. Black RE, Dykes AC, Anderson KE, Wells JG, Sinclair SP, Gary GW Jr, Hatch MH, Gangarosa EJ. Handwashing to prevent diarrhea in day-care centers. Am J Epidemiol 1981;113:445-51

52. Khan M, Shahidullah M, Ahmed WU, Barua DK, Begum T, Purification D, Rahman N. Intervention of shigellosis by hand washing. International Center for Diarrheal Disease Research scientific report no. 154. Dhaka, Bangladesh: December, 1981

53. Scientific Working Group. Environmental health and diarrheal disease prevention. Publication no. WHO/DDC/80.5. Geneva: World Health Organization, 1980:33

54. Banatvala JE. The role of viruses in acute diarrhoeal disease. Clin Gastroenterol 1979;8:569-98

55. Traveller's diarrhea [editorial]. Lancet 1981;1:777-8

56. Wolff HL, van Zijl WJ, Roy M. Houseflies, the availability of water, and diarrhoeal diseases. Bull WHO 1969;41:952-9

57. Newman G. Infant mortality: a social problem. London: Methuen, 1906

58. McDermott W. Modern medicine and the demographic disease pattern in overly traditional societies: a technological misfit. J Med Educ 1966;41:137-74

59. Levine RJ, Khan MR, D'Souza S, Nalin DR. Failure of sanitary wells to protect against cholera and other diarrhoeas in Bangladesh. Lancet 1976:2:86-9

60. Azurin JA, Alvero M. Field evaluation of environmental 
sanitation measures against cholera. Bull WHO 1974;51:19-26

61. Shrivastav JB. Prevention and control of cholera. In: Barua D, Burrows W, eds. Cholera. Philadelphia: W. B. Saunders, 1974

62. Sommer A, Khan M, Mosley WH. Efficacy of vaccination of family contacts of cholera cases. Lancet 1973;1:1230-2

63. Woodward WE, Mosley WH, McCormack WM. The spectrum of cholera in rural east Pakistan. 1. Correlation of bacteriologic and serologic results. J Infect Dis 1970;121(Suppl):S10-6

64. Levine MM, Black RE, Clements ML, Nalin DR. Cisneros L, Finkelstein RA. Volunteer studies in development of vaccines against cholera and enterotoxigenic Escherichia coli: a review. In: Holme T, Holmgren J, Merson MH, Mollby R, eds. Acute enteric infections in children: new prospects for treatment and prevention. New York: Elsevier/North-Holland Biomed Press, 1981:443-59

65. Levine MM, Gangarosa EJ, Barrow WB, Weiss CF. Shigellosis in custodial institutions. V. Effect of intervention with streptomycin-dependent Shigella sonnei vaccine in an institution with endemic disease. Am 3 Epidemiol 1976;104:88-92

66. Wahdan MH, Sérié C, Cerisier Y, Sallam S, Germanier R. A controlled field trial of live Salmonella typhi strain Ty 21 a oral vaccine against typhoid: three-year results. J Infect Dis 1982;145:292-5

67. Blacklow NR, Cukor G. Viral gastroenteritis. N Engl J Med 1981;304:397-406

68. Kapikian AZ, Wyatt RG, Greenberg HB, Kalica AR, Kim HW, Brandt CD, Rodriguez WJ, Parrott RH, Chanock RM. Approaches to immunization of infants and young children against gastroenteritis due to rotaviruses. Rev Infect Dis 1980;2:459-69

69. Powell DW, Field M. Pharmacological approaches to treatment of secretory diarrhea. In: Field M, Fordtran JS, Schultz SG, eds. Secretory diarrhea. Bethesda, Md. American Physiological Society, 1980:187-209

70. Rabbini GH, Greenough WB III, Holmgren J, Lönnroth I. Chlorpromazine reduces fluid-loss in cholera. Lancet 1979;1:410-12

71. Islam MR, Sack DA, Holmgren J, Bardhan PK, Rabbani GH. Use of chlorpromazine in the treatment of cholera and other severe acute watery diarrheal diseases. Gastroenterology 1982;82:1335-40

72. DuPont HL, Hornick RB. Adverse effect of lomotil therapy in shigellosis. JAMA 1973;226:1525-8

73. Nalin DR, Cash RA. Kaolin and cholera. Journal of the Pakistani Medical Association 1970;20:177-82

74. Bachtin M, Nelwan Suprapto, Sebodo T, Ismangoen. The use of antibiotics in childhood diarrhea. Journal of Tropical Pediatrics and Environmental Child Health 1979;25:101-3

75. Traveler's warning: entero-Vioform abroad. Med Lett Drug Ther 1975;17:105-6

76. Walder M. Epidemiology of campylobacter enteritis. Scand J Infect Dis 1982;14:27-33

77. Kohl S. Yersinia enterocoliticia infections in children.
Pediatr Clin North Am 1979;26:433-43

78. Anonymous. Antibiotic-associated colitis: the continuing saga. Br Med J 1981:282:1913-4

79. Pape JW, Kean BH, Mondestin B, Rohde J, Jasmin L, Johnson WD. The opening of a rehydration unit at the State University Hospital: a major step towards launching a national program for the control of diarrheal diseases in Haiti. Presented at the International Conference on Oral Rehydration Therapy, Washington, D.C., June 1983 (in press)

80. Hirschhorn $N$. The treatment of acute diarrhea in children - an historical and physiological perspective. Am J Clin Nutr 1980;33:637-63

81. Parker RL, Rinehart W, Piotrow PT, Doucette L. Oral rehydration therapy (ORT) for childhood diarrhea. Popul Reports [L]1980;8:41-75

82. McQuestion $M$, ed. Oral rehydration therapy: an annotated bibliography. 2nd ed. Scientific publication no. 445. Washington DC: Pan American Health Organization/World Health Organization, 1983:172

83. Santosham M, Daum RS, Dillman L, Rodriguez JL, Luque S, Russell R, Kourany M, Ryder RW, Bartlett AV, Rosenberg A, Benenson AS, Sack R. Oral rehydration therapy of infantile diarrhea. A controlled study of well-nourished children hospitalized in the United States and Panama. N Engl J Med 1982;306:1071-6

84. Nalin DR, Harland E, Ramlal A, Swaby D, McDonald J, Gangarosa R, Levine M, Akierman A, MacKenzie K, Johnson $\mathrm{B}$. Comparison of low and high sodium and potassium content in oral rehydration solution. J Pediatr 1980;97:848-53

85. Molla AM, Sarka SA, Hossain M, Molla A, Greenough WB III. Rice-powder electrolyte solution as oral therapy in diarrhoea due to Vibrio cholerae and Escherichia coli. Lancet 1982;1:1317-9

86. Patra FC, Mahalanabis D, Jalan KN, Sen A, Banerjee P. Is oral rice electrolyte solution superior to glucose electrolyte solution in infantile diarrhoea. Arch Dis Child 1982;57:910-2

87. Ifekwuniqwe A. Recent field experiences in Eastern Nigeria (Biafra). In: Blix G, Hofvander Y, Vahlquist B, eds. Famine: a symposium dealing with nutrition and relief operations in times of disaster. Uppsala: Almqvist and WiKsells, 1971:144-55

88. Nalin DR, Cash RA, Rahman M, Yunus M. Effect of glycine and glucose on sodium and water absorption in patients with cholera. Gut 1970;11:768-72

89. Patra FC, Mahalanabis D, Jalan KN, Sen A, Banerjee P. In search of a super solution: controlled trial of glycineglucose oral rehydration solution in infantile diarrhea. Acta Paediatr Scand 1983, (in press)

90. Shields DS, Nations-Shields $M$, Hook EW, Araujo JG, Auxiliadora deSouza M, Guerrant RL. Electrolyte/glucose concentration and bacterial contamination in home-prepared oral rehydration solution: a field experience in northeastern Brazil. J Pediatr 1981;98: $839-41$

91. Tekce B. Oral rehydration therapy: an assessment of mortality effects in rural Egypt. Stud Fam Plann 1982;13:315-27 
92. Islam MR, Greenough WB III, Rahaman MM, Choudhury AKA, Sack DA. Labon-gur (common salt and brown sugar) oral rehydration solution in the treatment of diarrhoea in adults. J Trop Med Hyg 1980;83:41-5

93. Mobarak AB. Egypt: mothers cut diarrheal deaths in half with homemade treatment. Salubritas 1982;6:1

94. Hendrata L, Rohde JE, Idrus D. Sodium concentration of home mixed rehydration solutions. Paediatr Indones 1980;20:91-2

95. Ellerbrock TV. Oral placement therapy in rural Bangladesh with home ingredients. Trop Doct 1981;11:179-83

96. International Study Group. A positive effect on the nutrition of Philippine children of an oral glucoseelectrolyte solution given at home for the treatment of diarrhea: report of a field trial. Bull WHO 1977;55: 87-94

97. Egemen A, Bertan M. A study of oral rehydration therapy by midwives in a rural area near Ankara. Bull WHO 1980;58:333-8

98. Barzgar MA, Ourshano S, Amini JN. The evaluation of the effectiveness of oral rehydration in acute diarrhoea of children under three years of age in West Azerbaijan, Iran. J Trop Pediatr 1980;26:217-22

99. Barzgar MA, Ourshano S, Nasser Amini J. The evaluation of the effectiveness of oral rehydration in acute diarrhea. J Egypt Public Health Assoc 1978;53(Suppl 5-6):82-104

100. Hirschhorn N, Denny KM. Oral glucose-electrolyte therapy for diarrhea: a means to maintain or improve nutrition? Am J Clin Nutr 1975;28:188-92
101. Cutting WAM, Omer RI, McLean SJ. A worldwide survey on the treatment of diarrheal disease by oral rehydration in 1979. Ann Trop Paediatr 1981;1:199-208

102. Molla AM, Molla M, Sakar SA, Rahaman MM. Intake of nutrients during and after recovery from diarrhea in children. In: Chen LC, Scrimshaw MS, eds. Diarrhea and malnutrition: interactions, mechanisms and interventions. New York: Plenum Press, 1983

103. Rohde JE. Therapeutic interventions in diarrhea. Food and Nutrition Bulletin 1981;3(4):34-8

104. Wray JD. Direct nutrition intervention and the control of diarrheal diseases in preschool children. Am J Clin Nutr 1978;31:2073-82

105. Mckeown T. The role of medicine: dream, mirage or nemesis? Nuffield, Eng: Nuffield Provincial Hospitals Trust, 1976

106. Mosley WH, Bart KL, Sommer A. An epidemiological assessment of cholera control programs in rural East Pakistan. Int J Epidemiol 1972;1:5-11

107. Rohde JE. Mother milk and the Indonesian economy. J Trop Pediatr 1982;28:166-74

108. Spady DW, Payne PR, Picou D, Waterlow JC. Energy balance during recovery from malnutrition. Am J Clin Nutr 1976;29:1073-8

109. Smith W. Educating the public on oral rehydration. presented at the International Congress on Oral Rehydration Therapy, Washington, D.C., June 1, 1983 (in press) 